CARLOS DE LA ISLA

\title{
¿Educación para la libertad o para el sometimiento?
}

$\mathrm{C}^{\mathrm{L}}$ título de estas reflexiones puede parecer anacrónico y E más acorde con las protestas estridentes del 68 contra la universidad y la educación superior. ¿Para qué plantear el problema de la libertad o el sometimiento por la educación en una época en que todo parece indicar que las universidades funcionan en paz y los estudiantes gozan de tranquilidad? Precisamente la causa de esta paz y tranquilidad es la incógnita, el móvil de esta consideración.

La universidad, que se define a sí misma como conciencia crítica de la sociedad, puede vivir momentos de paz porque tiene una conciencia tranquila, resultado del cumplimiento de su misión, que empieza en la reflexión crítica del saber, que transmite por la docencia, acrecienta por la investigación y participa por los canales de su extensión. La universidad puede vivir una conciencia tranquila y paz si se piensa a sí misma y piensa lúcidamente todas las dimensiones del ámbito social; si se convierte en inexpugnable oportunidad para la formación de hombres libres y comprometidos en justicia con su propio crecimiento y con el desarrollo de la comunidad. La universidad tiene derecho a disfrutar de paz si se afirma como utopía permanente, no en el sentido de la elaboración de modelos científicos y sociales muy hermosos, pero imposibles, sino en el sentido en el que la utopía plena es denuncia y anuncio: institución que conquiste la auténtica autonomía (sin dependencia económica o política que conlleva la dependencia ideológica) para ser en verdad libre y poder así denunciar, como juez insobornable, todo lo que haya que condenar en todos los 
niveles, desde el saber falso y el dogmatismo hasta las más sofisticadas fálsificaciones de las estructuras sociales, políticas y económicas. Pero al mismo tiempo libre también para anunciar las sentencias que se ajustan a la salud de sí misma y de la sociedad. Si la paz reinante en las universidades es por su misión cumplida, ique su paz sea perpetua!

Pero esa paz puede ser sólo aparente y de hecho la universidad puede estar viviendo una callada agonía, como piensa Vargas Llosa en sus "Reflexiones sobre una moribunda". Y hasta puede tratarse de la paz de una muerte paradójica, precisamente ahora cuando el hacinamiento en las universidades parecería mostrar mayor robustez institucional. Porque la universidad muere cuando deja de ser universidad (conciencia crítica, autónoma e insobornable de la sociedad) y se convierte en academia reforzadora de poderes políticos y económicos; muere cuando se derrumba como "recinto sagrado de la razón" (Jaspers) y se convierte en empresa que comercia con el pensamiento, en la que la ganancia económica es más importante que la búsqueda y la participación de las ideas vivas; muere cuando se autolimita, defensora de una ideología, por dominante que sea, y traiciona su esencia original de universalidad; muere cuando, deslumbrada por el espejismo de la utilidad, termina ciega, indiferente ante los difíciles caminos de la verdad; muere cuando confunde el servicio con el servilismo: la universidad sirve a la sociedad cuando es inteligencia que razona, estudia, analiza, discute, propone, defiende, latiga... Inteligencia activa que entiende a todos a favor de todos, pero se somete servilmente cuando se convierte en industria que programa sus procesos (carreras, grados, materias...) y sus productos (maestros, estudiantes, egresados...) de acuerdo a la demanda de un mercado regido por intereses de grupos.

Y el otro lado de la incógnita: la tranquilidad que gozan los estudiantes puede ser el resultado de una autoaprobación justificada; porque, conscientes del privilegio social, del alto costo social que significan todas las universidades públicas y privadas, responden con calidad a su compromiso, aprovechando el tiempo, los medios y las oportunidades que se les ofrecen para el desarrollo humano, científico y técnico, lo cual 
beneficia a los estudiantes mismos y debe emplearse también para resolver las carencias y problemas de las sociedades que siguen esperando.

Los estudiantes pueden gozar de una tranquilidad aprobada si defienden su derecho a ser diferentes, originales $y$ creativos, buscando una sociedad con imaginación y nuevas perspectivas. Y por eso condenan, con razón, al sistema establecido de uniformación que produce estudiantes y profesionistas en serie; con los mismos gustos, deseos e intereses, con las mismas ideas que generan cabezas idénticas, "cabezas intercambiables como sombreros" (Bergson). Ellos, en consecuencia, cuestionan las lecciones del maestro, el método de aprendizaje, el contenid o de los programas, la "verdad" oficial, la tradición. Pueden disfrutar de una justificada tranquilidad los estudiantes que se oponen a liderazgos prometedores y a profetismos verbales, decepcionados de sofismas y de palabras erosionadas y que han decidido aceptar sólo demostraciones de vida; los que repudian la idea de universidad fabricadora de títulos mágicos que abren las puertas del éxito, y piensan la universidad como la gran oportunidad para ser personas y cultivan la rara reflexión sobre el hombre y el contorno humano, porque saben que sigue siendo el saber más importante: el arte de ser persona; los que se rebelan al mandato de las sociedades programadas: "está prohibido pensar" y encuentran en la conciencia crítica la única defensa de "la libertad que se ha agotado en mentiras" (Berdiaef); los que aceptan el compromiso para luchar por una sociedad más libre y más justa, pero odian ser esclavos de totalitarismos ideológicos, políticos o económicos, porque se niegan a pertenecer a una sociedad tan común en "el siglo XX que ha contemplado la aparición del hombre rebaño y de los caudillos semejantes a los dioses" (B. Russell).

Si estas conciencias y actitudes universitarias generan la tranquilidad existente de los estudiantes ique su tranquilidad sea permanente! Pero esa quietud también puede ser fruto de los sistemas de amansamiento, alienación o, como diría Marcuse, de idiotización. Pensemos en algunos ejemplos de sometimiento $y$ en sus mecanismos que no pretenden ser ni exhaustivos ni de vigencia cotidiana o universal: los sedantes 
que se han obsequiado generosamente para calmar los impulsos de los jóvenes que piensan, que dudan, que cuestionan, que condenan, que remueven... que molestan. Sedantes tan efectivos como el aplauso social, identificable por las altas contrataciones a los "dóciles que saben hacer bien lo que se les manda", sin preguntar ni replicar, la gratificación económica disfrutable con liberalidad y fuera de las fronteras, promesas de cargos públicos reservados a los "brillantes y fieles", donaciones abundantes para propiciar la "alegría juvenil", los viernes sociales, los sábados felices y los domingos mortales, "bebidas inofensivas" y sus auxiliares para instrumentar las competencias interuniversitarias: charreadas, corridas, comidas, bebidas, bailes, campeadas, premios en efectivo para carreras de coches (con metas abiertas y disfrazadas), exhibiciones de modas y modelos...; para no hablar de otra clase de sedantes y excitantes que fueron distribuidos y consumidos generosamente en las universidades más "inquietas" de aquel 1968, y con los cuales se obtuvieron satisfactorios resultados de amansamiento, idiotización (procedimiento y efectos de ninguna manera exclusivos de ese año). Algunos ejemplos más, fruto del mismo proceso: estudiantes conservadores y repetidores de ideas intactas, transmitidas por los custodios del "orden establecido", quienes se han convertido en recipientes incondicionales de todo lo que se da, se pasa y traspasa, "como camaleones con la boca siempre abierta los que no cierran la inteligencia ante nada" (Bisset); predestinados que deben prepararse "para su sitio dispuesto desde el principio del mundo" en la empresa familiar o en el escalafón de la gran maquinaria, y que transitan las aulas y las bibliotecas, porque la universidad da imagen, estilo, modales y hasta algunos conocimientos que justifican el espeso sillón del largo despacho del futuro ejecutivo que ha de ejecutar dócilmente las órdenes de arriba; consumidores consuetudinarios de los modos y las modas (también intelectuales) inventados, ofrecidos o impuestos por los modeladores en turno de "medio social"; los que juegan la competencia individualista, liberal, y se fijan como meta llegar a ser el número uno y resonar en el eco de las aulas y en las gacetas informativas, sin importar la calidad de los escalones que ascienden o las estrategias del camino, y olvidando, por 
supuesto, esa multitud innumerable y angustiada de la sociedad que nunca consideró a la universidad como gratificación de egoístas; los que aman "la seguridad" y siguen, por reflejos condicionados, los caminos mil veces recorridos y desgastados, como ovejas mansas, ojo en tierra, tras el badajo del pastor; los manejados sin resistencia por los criterios de utilidad de los que se encargan de dictar el programa de valores sociales y optan por los conocimientos útiles, prácticos, vendibles, para los que "el saber, es oro" y aprenden con avaricia, inquietos sólo por preguntar: ¿esto para qué me sirve?, es decir, ¿en cuánto puede venderse?, porque han decidido ser especialistas técnicos muy bien pagados, es decir, mercancía muy cara... Breves ejemplos de sometidos que también pueden ilustrar sobre la causa de la tranquilidad estudiantil reinante.

Desde esta perspectiva no parece nada claro que las universidades estén, no digamos comprometidas, sino al menos empeñadas en la búsqueda del desarrollo de personas realmente libres por el cultivo de métodos y actitudes que conduzcan a maestros y alumnos a descubrir más que a repetir, a imaginar e inventar más que a memorizar, a crear en vez de copiar. Esto también se muestra en la preferencia oficial por técnicas de enseñanza verticales, receptivas, dirigidas al "engorde de cerebros" (Gusdorf), en la corona de laureles colocada en las sienes de estudiantes que mejor grabaron el mensaje o mejor reprodujeron la tesis y hasta la personalidad del maestro, y en contraste, se obstaculizan y hasta reprueban las actitudes y métodos de confrontación de ideas, de cuestionamiento, de análisis abierto, de diálogo horizontal, es decir, todo lo que conduce al desarrollo del pensamiento crítico y, por tanto, a la afirmación de personas y personalidades libres y diferentes que, por diferentes, analíticas y críticas aporten perspectivas nuevas y nuevas interpretaciones sobre los problemas y el mundo, empezando por el suyo propio.

"Esta originalidad", dice Paul Legrand, "que constituye el interés de la aventura humana y que hace que la existencia valga la pena de ser vivida está sistemáticamente acosada por la mayor parte de los sistemas educativos. La universidad está encargada de hacer reinar el orden intelectual; pero este orden, contrariamente a lo que constituye un verdadero orden, no 
busca la coexistencia de las diferencias, el equilibrio y armonización de los contrarios, sino que se apoya en la imposición de modos unificados del pensamiento, del sentimiento y de la conducta. Lo que se rechaza es el individuo que piensa por sí mismo, que tiene sus gustos propios y desarrolla su manera personal de concebir sus relaciones con el mundo, comprendidos aquí los poderes. A quien se busca y se favorece es al hombre obediente y sumiso al modelo. La educación, tal como está concebida y funciona en la mayor parte de los países, es el instrumento ideal para esta empresa de uniformización de los espíritus y modelado de las personalidades.

Uno de los puntos en que el carácter de la educación moderna se manifiesta es éste: en las declaraciones oficiales se pretende formar al hombre en la plenitud del hecho humano, aunque, en realidad, la educación se da con la intención de modelar al individuo de manera tal que haga suyas las ideologías, asimile los complejos de superioridad e inferioridad, adopte el sentido de las jerarquías que desarrollan entre los individuos el sentimiento y orgullo de pertenencia nacional y lòs hace fáciles de gobernar".

$Y$ cuando la universidad se dedica a moldear lo hace con exquisita perfección, como el más fino y detallado troquel de monedas humanas manejables en la teoría de los precios. Para esta manufactura y troquelado de "personalidades" se emplean las técnicas más sutiles de condicionamiento e inducción de ideas, de ideologías, de gustos y elecciones. Todo lo que se llama pensar y obrar queda minuciosamente determinado. Resultado: se obtiene la conducta que se desea para los fines que se desean. Paulo Freire, lúcido crítico de la "pedagogía del oprimido", afirma: "La relación entre el educador y el alumno es de sujeto a objeto, es decir, que este último se limita a recibir los conocimientos del primero. Consecuentemente el educador, el que sabe, el que separa el hecho de enseñar del de aprender es siempre el que piensa, el que sabe, el que habla; el alumno tiene la ilusión de hablar repitiendo lo que el educador ha dicho; tiene la ilusión de saber puesto que el educador sabe... Por esto, en general, el alumno no es reticente ni indócil, no experimenta dudas, no aspira a conocer la razón de ser de los hechos, no va más allá de los modelos propuestos, no 
condena una burocracia que genera mediocridad, no rechaza ser un objeto. Muy por el contrario, en este tipo de educación el buen alumno es el que repite lo que se le dice, que rechaza todo pensamiento crítico, que se adapta a los modelos establecidos, que encuentra agradable ser un rinoceronte". Y además el autor nos remite a El Rinoceronte de lonesco.

La educación para la libertad y el proceso de sometimiento son antagónicos como lo son la educación y el amaestramiento: la educación se orienta hacia "el hombre que supera infinitamente al hombre" (Pascal) y propicia el desarrollo de las potencialidades singulares de hombres que se comprometen con su crecimiento personal, con su comunidad y con su historia; el amaestramiento, óptimo método para el control y el sometimiento, produce la degradación por reflejos condicionados y por reforzamientos positivos y negativos hasta obtener la sumisión y el manejo deseados: igran privilegio de quienes emplean y manejan a las masas! A través del amaestramiento se logra la proximidad en las conductas del animal al hombre y del hombre al animal. Resulta de sumo interés para nuestras reflexiones recordar cómo, por medio de la teoría de los reflejos condicionados, se obtienen las reacciones y los comportamientos que se desean tanto de animales que han de vivir en casas "refinadas" o que han de mostrar sus encantos en el circo, como de niños, adolescentes y adultos igualmente amaestrados y domesticados para actuar en el gran circo. Importa enfatizar el idéntico procedimiento empleado con personas y animales: obtenido el comportamiento que se busca, la gratificación es inmediata; reforzamiento positivo (a la foca que salta el aro se le premia con la sardina... al niño que permaneció inmóvil se le gratifica con el chocolate... al estudiante que mejor repite...) hasta formar el hábito y finalmente la conducta planeada, la vida programada. Más impresionante aún es el proceso de domesticación por lo que éste tiene de represión y destrucción de la energía vital. El objetivo es el mismo: la conducta, según el modelo pensado; el procedimiento también es el mismo: se provoca el acto con el estímulo artificial, se repite sistemáticamente hasta formar el hábito, la conducta, la vida..., el reforzamiento es el que cambia de positivo a negativo: cuando el león expresa su temperamento 
natural, no deseado porque asusta a los consumidores de diversión, se le aplica el látigo, la corriente eléctrica, el hambre tranquilizante, hasta que sus modales dejan de ser salvajes y se vuelven aceptables, sociables. De manera idéntica se procede para amansar al buen estudiante inquieto que objeta, que cuestiona, que pide evidencias, que piensa diferente, que razona: se le aplica el látigo de la desaprobación, reprobación y represión... reforzamientos negativos, hasta eliminar su conducta "salvaje" y obtener modales aprobados, tolerables, sociales.

No comparto las tesis del determinismo sociológico, pero no puedo negar la eficacia de los métodos empleados para esterilizar temperamentos y personalidades creadores por medio de sistemas y subsistemas autoritarios, y, en concreto, por las universidades que son extensión de poderes políticos, económicos e ideológicos. Por eso, uno de los perfiles más repugnantes de la universidad es aquel que pueda mostrarla como instrumento de dominación: universidad sometida y sometedora; se somete al poder establecido y somete a sus integrantes para perpetuar el sometimiento.

Ya en 1929 Giovanni Papini denunciaba así a la universidad: "En la universidad tenemos la inmovilidad del espíritu, obligado a repetir en vez de buscar; el desastroso esfuerzo para aprender con métodos imbéciles muchísimas cosas inútiles, y el ahogo sistemático de toda personalidad, originalidad e iniciativa en el negro mar de los programas uniformes... La universidad enseña mal, porque enseña a todos las mismas cosas del mismo modo y en la misma cantidad sin tener en cuenta las infinitas diversidades de ingenio, de raza, de extracción social, de edades, de necesidades". "Los estudiantes universitarios deberían convertirse en libres discípulos y colaboradores de sus maestros..." "Yo quisiera que todas las universidades se convirtieran en tantos seminarios como materias se enseñan en ellas. Lo importante para mí es que la universidad no sea, como hoy, una manufactura estatal de candidatos al atontamiento o al empleo."

Más de cincuenta años después de esta denuncia la mayoría de las universidades no sólo no se han liberado de ser "manufactura estatal", sino que, en forma embozada y a veces 
abierta, por imposición del poder que subvenciona y, en ocasiones, por gustosa iniciativa, se dedica a formar estudiantes y a realizar investigaciones con evidentes fines de dominio político y económico, nacional y transnacional; también, como manufactura comercial, está al día en la "formación" (dar la forma requerida) de profesionistas según los requerimientos y especificaciones precisas de las grandes empresas empleadoras y es responsabilidad de estas universidades que sus "formados" sean buenos funcionarios, es decir, que funcionen con entera perfección, integrados al movimiento de la gran maquinaria, como lo señala Berdiaef en El destino del hombre contemporáneo: "La civilización tecnológica exige del hombre únicamente el cumplimiento de una u otra función y no quiere saber nada del hombre en sí mismo. Le interesan solamente las funciones que el hombre pueda cumplir." En expresión de W.H. White Jr., en este sistema de funciones (opuesto a creaciones) el más aplaudido, el más solicitado, el mejor es el "hombre bien redondeado", porque su redondez propicia la rotación precisa, tecnocrática mente definida. Las aristas propias, las innovaciones, la imaginación creadora, las decisiones responsables, el riesgo, en una palabra, las personas no caben en esta estructura herméticamente armada. Por el contrario, en ese quehacer de fabricación de piezas exactas, hechas para el funcionamiento de la estructura del poder, la ideología y el especialismo juegan un papel predominante: "el especialismo, comentaba un estudiante con ingenio; se propone lograr insectos mediocres"; y explicaba: "el insecto realiza sus funciones con microscópica perfección, pero siempre hace lo mismo y del mismo modo; el especialista nunca logra la perfección del insecto, pero sí lo imita al repetir siempre lo mismo y del mismo modo". Y en este proceso de especialización para alcanzar el redondeamiento y la domesticación, el pensamiento se maneja como el arma irresistible de poder: "La ideología de la clase dominante - dice Tierno Galván- en la mayoría de los países del mundo se ha convertido en el resultado de una manipulación consciente por parte de las minorías en el poder, que no creen en nada, salvo en el poder mismo en cuanto defensa y expresión de sus intereses. Detrás de las ideologías manipuladas existe una ideología única: el poder y sus privilegios definen cual- 
quier ideología." En forma semejante E. Mounier se refiere a la ideología como herramienta de dominio: "Los sistemas de partidarismo ideológico no hacen más que someter al creador deficiente a conformismos exteriores y reducirlo a ser un fabricante sobre modelos dados..." "Nos oponemos a cualquier régimen totalitario de escuela que, en lugar de preparar progresivamente a la persona para usar de su libertad y responsabilidades, la esteriliza en el inicio, doblegando al estudiante a pensar por delegación, a actuar por órdenes y a no tener otra ambición que estar colocado, tranquilo y considerado en un mundo satisfecho..." "No existe tiranía más cruel que la que se realiza en nombre de una ideología."

Cuando el estudiante se siente como materia usada, moldeada, redondeada es comprensible que no se sienta sujeto responsable de sus actos y que incluso se hunda en esa expresión de nihilismo y pérdida total en la que lo único que importa es que nada importa; como aquella actitud que Becket expresa a través del protagonista de su Malone muere: "Poco importa que haya nacido o no, que haya vivido o no, que esté muerto o sólo agonizante; haré lo que siempre he hecho con la ignorancia de lo que hago, de quién soy, de dónde soy, de si soy... y quizás esté en el momento en que vivir es errar en completa soledad."

La pedagogía de la domesticación desemboca finalmente en el nihilismo o en el pragmatismo que declara: nada importa la verdad de lo que pienso mientras lo que pienso funcione, $y$ en todos los casos termina en el sometimiento a los poderes que manejan la estrategia cuidadosa de la conducción hacia los objetivos por ellos deseados.

La educación para la libertad, única verdadera educación de personas, supone ante todo la clara conciencia de la sujeción, porque "estamos tan habituados a ser esclavos que pensamos que es nuestro estado natural" (H. Newton); y porque "vivimos en una época de decadencia de la libertad, la cual se ha agotado en mentiras" (Berdiaef). Por eso todo intento de libertad se inicia en el análisis crítico. Si no se da la liberación de los condicionantes o determinantes del pensamiento no existirá libertad en la acción. Así, la "pedagogía de la liberación"(Freire) exige, como condición inicial, ese método analí- 
tico y crítico en el que la relación educador-educando, en todos los niveles, es de confrontación de ideas y personalidades en el camino de la búsqueda de la verdad que sí existe, aunque resulte cada vez más difícil despojarla de todos sus encubrimientos y disfraces: "la dificultad para descubrir la verdad no significa que no haya verdad por descubrir" (B. Russell). Y estas verdades, fruto del diálogo entre personas (no las "verdades dadas") constituyen el fundamento de la libertad. "Precisa ya que dándole la espalda al erudito fomentemos la técnica del parto de las almas", dice Vasconcelos; y es que el erudito es el producto del proceso receptivo, vertical, acrítico que conduce a la acumulación de conocimientos y a la repetición: métodos y técnicas para el sometimiento. "El parto de las almas" significa, por el contrario, la gestación personal por el cuestionamiento, por el análisis crítico, por el diálogo, de esa verdad que por gestarse así se convierte en sentido y móvil de la existencia, en compromiso espontáneo que anula toda neutralidad de pensamiento y de acción.

Es muy frecuente el planteamiento de la pregunta: ¿por qué la universidad fomenta la neutralidad de la ciencia y del científico? ¿Por qué con gran frecuencia, en vez de comprometerse con el ideal de una sociedad más libre y más justa, contribuye al reforzamiento de las diferencias sociales, de las injusticias sociales? Pienso que la respuesta está en el mismo campo de nuestra reflexión: quien sólo tiene ideas de otros, ideas prestadas y se comporta como banco que guarda "valores" ajenos ("educación bancaria": Freire), es comprensible que permanezca indiferente (ya sea individuo o institución), porque no puede ser sujeto de sus propios pensamientos, sino que más bien se encuentra sometido a la dictadura del pensamiento ajeno. Pero, de hecho, no existe la pretendida y cómoda neutralidad de la ciencia o del científico, del maestro, del estudiante o de la universidad. Lo que existe es indiferencia o compromiso: no comprometerse con la justicia y la libertad sociales no es neutralidad, es compromiso con los intereses individuales $y_{0}$ de grupo del "orden establecido" que tanto les beneficia. La ciencia, por su estructura y contenido, si es ciencia, es verdadera y es universal, no neutral, y en cuanto a su empleo es evidente que el político, el estudiante y hasta el 
científico no la consideran con intocable neutralidad, sino que la manejan como arma en las luchas que se proponen. En este mismo sentido la universidad tampoco puede ser neutral: se afirma como instrumento de dominación junto con todas las estrategias y técnicas ya comentadas (educación para el sometimiento), o se compromete con sus propias ideas que, como inteligencia libre o liberada, ha concebido después de leer y "leer en el mundo para demostrar los libros"(M. Foucault). La universidad que así piensa y es coherente con sus pensamientos, es una universidad libre que educa para la libertad; porque la educación que aspira a la libertad no se da por una mera declaración en los objetivos institucionales. Para educar en la libertad la universidad ha de ser libre y generar sus propias leyes (autonomía) y tener conciencia de su responsabilidad; libre para definir su campo de estudio y el ejercicio del saber en la docencia a través del conocimiento de las necesidades y conveniencias de toda la sociedad; libre para eliminar la investigación a destajo y por pedido cargado de especificaciones de los consumidores, para dedicarse a estudiar aquellos ámbitos más urgentes que perciba su propia visión universal y totalizadora....

La educación para la libertad supone una jerarquía definida de fines educacionales: cuando se piensa en sus grandes objetivos se ha de pensar primero en el desarrollo del hombre y secundariamente en sus funciones; es decir, lo más importante es afirmar y robustecer al sujeto que ha de manejar los instrumentos técnicos. Esta es también la base de la llamada educación para eí futuro: en un mundo en el que las técnicas más recientes tienen tan corta duración, en el que los conocimientos prácticos o funcionales se hacen muy pronto obsoletos, en el que el cambio es vertiginoso e imprevisible, la educación debe pensar en ese hombre que debe afrontar con lucidez intelectual y dignidad humana la novedad o sorpresa de la hora siguiente en todos los planos de la existencia. Todo esto parece válido, por supuesto, si pensamos en una educación humana y no en el adiestramiento para el mercado.

Alguien podría sugerir que la universidad, para cumplir su misión, debiera conservarse en una torre de marfil o en una fortaleza inexpugnable y así permanecer intacta e incontami- 
Educación: ¿libertad o sometimiento?

nada; este absurdo equivaldría a custodiar la mente en un recipiente de cristal, desconectada del cuerpo que debe dirigir sería una cómoda fuga de la realidad que así no podría comprenderse ni menos orientarse.

Si se entiende a la universidad como educadora, orientadora y ordenadora ha de estar inmersa en su comunidad, en su sociedad, para percibir el desorden que debe ordenar sin hacerse parte del mismo; necesita situarse dentro del sistema que ha de contemplar con perspectiva crítica, pero no debe permitir ser sometida por las fuerzas del sistema; debe conocer las necesidades de su comunidad para servirla, pero sin caer en el servilismo. En síntesis, la universidad, penetrada del mundo real, debe mantener la independencia para ser libre y educar en la libertad.

Difícil tarea para las universidades que no han seguido la dirección de la libertad; pero tarea muy deseable como refugio y esperanza de libertad en una época en que los poderes político y económico, a veces con descaro, a veces con sutileza y siempre con abundantes justificaciones, todo lo programan, lo controlan, lo dominan. 